\title{
LOS INCIOS DE LA ORGANIZACIÓN POLÍTICA EN LAS VILLAS DE LA CIUDAD DE BUENOS AIRES (1955-1970).
}

\section{THE BEGINNINGS OF POLITICAL ORGANIZATION IN THE SHANTY TOWNS OF THE CITY OF BUENOS AIRES.}

v. 9, n. 1 [15]

jan/abr (2017)

Dossiê "Villas Miseria, Favelas y

Asentamientos: nuevas rutas en

Historia Urbana"
Eva Camelli

Facultad de Ciencias Sociales, Universidad de Buenos Aires evacamelli@yahoo.com.ar

\section{Resumen}

El artículo tiene por objetivo analizar las primeras organizaciones territoriales surgidas en las villas de la Ciudad de Buenos Aires a partir de la proscripción del Partido Peronista. En el análisis de las organizaciones políticas villeras resulta ineludible observar las acciones estatales dirigidas hacia estos espacios urbanos. De este modo, el artículo indaga los inicios de la organización política en las villas de Buenos Aires y su relación con los gobiernos de turno entre 1955 y 1970.

\section{Palabras clave}

Proscripción peronista. Organizaciones villeras. Plan de erradicación.

\section{Abstract}

The article aims to analyze the first territorial organizations set up in the shanty towns of Buenos Aires from the proscription of the Peronist Party. In the analysis of political organizations it is unavoidable observe state actions directed towards these urban spaces. In this way, the article explores the beginnings of political organization in the shanty towns of Buenos Aires and its relationship with the governments between 1955 and 1970.

\section{Keywords}

Peronist proscription. Organizations of the shanty towns. Eradication plan. 
El presente artículo tiene por objetivo analizar las primeras organizaciones territoriales surgidas en las villas de la Ciudad de Buenos Aires a partir de un hecho de central importancia en la historia política argentina como fue la proscripción del Partido Peronista.

El peronismo surgió en Argentina para fines de la década de 1940 como un movimiento político liderado por Juan Domingo Perón, quien durante sus dos primeros gobiernos (19461955) llevó adelante una política económica redistributiva a favor de los sectores populares, en especial de la clase trabajadora.

El segundo mandato gubernamental de Perón fue derrocado mediante un golpe de Estado y a partir de allí se proscribió al Partido Peronista, situación que perduró hasta el año 1973, cuando por primera vez en 18 años el peronismo pudo participar de elecciones libres y abiertas.

Las villas argentinas surgieron en la década de 1930 y crecieron durante los dos primeros gobiernos peronistas a causa de la intensificación del modelo de industrialización por sustitución de importaciones que concentró en las grandes urbes del país las nuevas fuentes laborales. Las migraciones motivadas por búsqueda de mejoras en las condiciones de trabajo fueron una respuesta de los sectores populares a las ofertas laborales asentadas centralmente en el Área Metropolitana de Buenos Aires.

Las organizaciones villeras se fueron creando paralelamente a la instalación de las villas con el objetivo de proveer al barrio servicios urbanos básicos, como la luz y el agua. En esas primeras experiencias de organización barrial fueron madurando adscripciones políticas que el peronismo logró hegemonizar. ¿Cómo impacta la proscripción del peronismo en las villas de la Ciudad de Buenos Aires? ¿Qué características adquiere la organización colectiva en el territorio a partir de entonces?

En el análisis de las organizaciones políticas villeras resulta ineludible observar las acciones estatales dirigidas hacia estos espacios urbanos, que paradojicamente comenzaron inmediatamente después de derrocado el peronismo (en el año 1956) ¿Cómo abordaron los diferentes gobiernos sucedidos en este período el problema de las villas en la ciudad?

De este modo, el artículo indaga los inicios de la organización política en las villas de Buenos Aires y su relación con los gobiernos de turno entre 1955, momento en que se proscribe el peronismo, y 1970, momento en que comienza un lento proceso de desandar la proscripción en las villas ya que para fines de los sesenta comienzan a aparecer Juntas Vecinales identificadas con el peronismo.

La estrategia metodológica utilizada para la investigación buscó articular fuentes primarias y fuentes secundarias de información. Las fuentes secundarias constaron de la selección de textos académicos sobre el tema. Las fuentes primarias constaron de documentos históricos y entrevistas en profundidad a habitantes de villas de Buenos Aires que participaron en la política partidaria de los años sesenta. La puesta en diálogo de las diferentes fuentes de información ofreció una mirada complementaria para analizar la historia política en las villas 
durante la proscripción peronista.

El artículo presenta un primer apartado abordando el contexto histórico y las implicancias que tuvo en las villas; seguidamente se analiza el impacto en la construcción identitaria del villero durante la dictadura, pasando a consolidar un nuevo sector social dentro de la sociedad civil; en el tercer apartado se analiza a la primera organización política villera; y, finalmente se trabajan los planes estatales dirigidos hacia las villas durante el período estudiado.

\title{
1. Contexto nacional: a desperonizar
}

El golpe de Estado iniciado el 23 de septiembre de $1955^{1}$ tuvo una característica distintiva en relación a los anteriores golpes acontecidos en el país: la autodenominada Revolución Libertadora se propuso poner fin a un actor político de relevancia insólita hasta el momento. Eliminar al peronismo de la trama política nacional fue la ambiciosa meta de este gobierno de facto. En los golpes de Estado anteriores se habían expuesto agudas disputas políticas, pero en ningún caso se atacó de manera tan explícita y directa a un proyecto político que, además, contaba con una extendida aceptación popular.

La herramienta de la cual se sirvieron los militares para encausar la anhelada desperonización (Lanusse, 2009,p. 63; Gillespie, 1998, p. 43; James, 1999, p. 78)² del país fue la proscripción del Partido Peronista como así también el exilio forzado de su líder. Las personas identificadas con el peronismo fueron víctimas de un arsenal de acciones humillantes y represivas de diversa índole, a través de las cuales la dictadura conjugó la violencia tanto simbólica como directa. Ejemplo de ello es una de las primeras acciones del gobierno de facto de Pedro Eugenio Aramburu: ${ }^{3}$ el secuestro y posterior desaparición del cadáver de Eva Duarte de Perón.

\begin{abstract}
El secuestro y la desaparición del cadáver de Evita fue sólo una de las muchas medidas que el gobierno de Aramburu tomó como objetivo de «desperonizar» el país. Así, entre fines de 1955 y comienzos de 1956 fueron encarcelados cientos de dirigentes peronistas, se redobló la actividad de comisiones especiales creadas para investigar irregularidades cometidas durante el régimen depuesto, se intervino la CGT, se disolvió la Fundación Eva Perón, se derogó la Constitución de 1949, se prohibió ocupar cargos gubernamentales o sindicales a quienes lo hubieran hecho antes de septiembre de 1955 y el Partido Peronista fue declarado ilegal (Lanusse, 2009, p. 63).
\end{abstract}

\footnotetext{
${ }^{1}$ Los bombardeos a la Plaza de Mayo del 16 de junio de ese año fue un intento fallido anterior de arrebatar el poder. Para un análisis de los hechos véase Lucas Lanusse (2009, p. 37 y siguientes).

${ }^{2}$ En rigor, Gillespie se refiere al hecho en esta página aludiendo a que luego de 1955 el peronismo tuvo que "enfrentarse a los intentos de ahogarla y suprimirla", mientras James habla de "revolución antiperonista".

3 Fue el sucesor de Eduardo Lonardi, quien lanzara la Revolución Libertadora el 16 de septiembre en Córdoba y que asumió la presidencia el 23 de ese mes, bajo la consigna "ni vencedores ni vencidos". A menos de dos meses, el 13 de noviembre, fue desplazado de la presidencia por la presión de sectores liberales de las Fuerzas Armadas que confiaban en la figura de Aramburu para culminar de una vez y para siempre con la huella peronista. Para un detallado análisis de las negociaciones entre Lonardi y el movimiento sindical peronista véase Daniel James (1990, p. 69-82).
} 
Indefectiblemente este ataque contra el peronismo no demoró en mostrar reacciones. A contramano del objetivo deperonizador, la Revolución Libertadora intensificó la identidad peronista en el seno de las clases populares, ahora realizada en términos desafiantes y al margen de la legalidad. El reforzamiento de esta identidad se construía sobre las mejoras obtenidas durante los gobiernos peronistas y sobre la reacción a los agravios recibidos por parte de la dictadura militar (Gillespie, 1998, p. 46).

Con el peronismo proscripto y sus principales gremios intervenidos, surge lo que pasó a la historia como la Resistencia Peronista, la cual puede definirse como un proceso de articulación política semiclandestino, fundamentalmente espontáneo y localizado que actuó como respuesta defensiva a la represión y hostigamiento dirigidos a la clase trabajadora peronista. "No por casualidad, 1956 sería el año en que la «Resistencia» terminara de afianzarse, mediante una serie de prácticas inorgánicas que iban desde el lanzamiento de huelgas y sabotaje, a la realización de pintadas o la colocación de artefactos explosivos" (Lanusse, 2009, p. 77). La Resistencia adoptó como eje de su lucha política la recuperación de los sindicatos, "columna vertebral" del peronismo (Gillespie, 1998, p. 57; James, 1999, p. 94). Esta estrategia promovió las organizaciones de base en diferentes lugares de trabajo, consolidando comisiones internas y cuerpos de delegados que plasmaban un modo alternativo de representación política vinculada al peronismo que era imposible expresar en las cúpulas sindicales (Snitcofsky, 2011, p. 55$) \cdot{ }^{4}$

Los villeros, como la mayoría de los sectores integrantes del campo popular, se sintieron identificados con el peronismo y, en consecuencia, sintieron el agravio de la proscripción peronista en primera persona.

Vale detenerse brevemente en este punto: teniendo en cuenta el apoyo brindado por los villeros al peronismo, cabe interrogarse acerca de las políticas destinadas a este sector. Concretamente: ¿qué hizo el gobierno peronista ante esta nueva situación planteada en el entramado urbano de la ciudad? Encontramos una ausencia de políticas destinadas específicamente al sector villero. Las acciones efectivamente realizadas por el peronismo fueron destinadas a obreros y empleados formales sin planificar un modo de abordar la problemática de la vivienda para la novedosa y creciente situación urbana plasmada en las villas citadinas. Es probable que el gobierno haya conjeturado que la propia dinámica redistributiva impulsada desde su política económica acomodaría a esas familias en lugares dignos de vivienda. ${ }^{5}$

$4 \quad$ Existe consenso en ubicar el desarrollo de la Resistencia Peronista entre los años 1956, a partir de la ofensiva de Aramburu, y 1960, momento en que el peronismo logra recuperar los sindicatos (luego de finalizada la intervención y centralmente tras el Congreso Normalizador de la CGT de 1957). Lanusse (2007, p. 51) identifica este desplazamiento de la representatividad del peronismo en el contexto de proscripción como un "triunfo" del ala sindical del peronismo y una "derrota" de la Resistencia, germen de lo que el autor denomina "Tendencia Revolucionaria dentro del peronismo". Este cambio no hizo otra cosa que encauzar la disputa política en torno al peronismo en un espacio que fue atravesando un proceso de paulatina burocratización.

${ }^{5}$ De todas maneras, si bien los villeros no fueron alcanzados por el derecho a la vivienda, la valoración de 
Asimismo, el proceso de conformación y crecimiento de las villas en Buenos Aires contuvo la convicción de los pobladores sobre la transitoriedad de la residencia en estos lugares. La esperanza y las expectativas sobre el ascenso social que podía ofrecer un trabajo en la ciudad, hacía pensar que el paso por la villa era sólo el primer momento en el proceso migratorio. Como explica Pastrana (1980, p. 129).

las mejores condiciones objetivas de vida de los sectores populares durante el gobierno peronista tenían como consecuencia que los habitantes de estos asentamientos consideraran como algo transitorio el hecho de habitar viviendas en malas condiciones en terrenos ilegalmente ocupados, puesto que se percibían como parte de la clase trabajadora en continuo ascenso en su nivel de consumo.

La esperanza gestada por los pobladores en torno a la transitoriedad del pasaje por la villa se vio completamente abandonada con la llegada del nuevo gobierno de facto. Lo que se pensó como transitorio empezó a configurarse como lugar de residencia permanente. Entre la convicción de la villa como tránsito obligado y la difícil tarea de acceso a la ciudad forma/ ${ }^{6}$ es que se lleva a cabo el golpe de Estado que impacta definitivamente de manera desfavorable en los villeros.

\section{Del tránsito a la permanencia: la conformación de un "nuevo" sector social}

La confianza depositada en el gobierno peronista por parte de los villeros hizo creer que el paso por la villa sería sólo un lugar de tránsito, hasta comenzar el anhelado ascenso social. ${ }^{7}$ Este rasgo hizo innecesario la construcción de una identidad propia como sector específico dentro del entramado social, ya que se la transitaba como una situación provisoria, un mientras tanto, un entre: la villa era el paso obligado entre el lugar de origen y la aspirada vivienda de la ciudad formal.

La caída del peronismo tuvo un impacto muy fuerte en la subjetividad de la población villera. Si una de las variables que sostenía la convicción en el paso transitorio por la villa era la existencia de un gobierno popular que le garantizaría una mejora en su calidad de vida, la caída del mismo fue acompañada por la resignación de los villeros de arribar a la ciudad formal. Este proceso fue paulatino y fue configurando una nueva conciencia, en donde la zona de residencia fue ganando un lugar de identidad particular, muy a pesar de todos y cada uno de los habitantes. Apropiarse de un espacio pensado en términos de mediano y largo plazo, que el paso del tiempo expresó definitivo para más de una generación, configuró un nuevo modo de autodefinirse y de pensarse.

otras instancias de derechos sí conquistados y disfrutados hicieron crear y mantener una identificación con el peronismo, aún encontrando el escollo de no poder emigrar de la villa como lugar de residencia.

${ }^{6}$ La ciudad formal es aquella que se enmarca en las normas legales y urbanas, en contraposición a la ciudad informal, que son aquellos tramos de ciudad que, como las villas, desafían dichas normas.

7 Esta idea se encuentra desarrollada en la investigación del antropólogo Hugo Ratier, Villeros y villas miseria (1973).

(c) Urbana: Rev. Eletrônica Cent. Interdiscip. Estud. Cid

Campinas (SP)

v.9, n.1 [15] p.182-203

ISSN 1982-0569 
Sin ánimos de deslegitimar la expectativa de ascenso social que el peronismo despertó entre los villeros, resulta llamativo que una población que en términos urbanos recibió escasa o nula asistencia habitacional de parte del gobierno popular construya y sostenga a lo largo de los años la ilusión de que el peronismo resolvería su situación residencial. Indudablemente esta confianza fue cimentada por mejoras y beneficios recibidos por las familias villeras en otros espacios sociales, como en la seguridad social, en el trabajo, en los servicios públicos y en las acciones de beneficencia. La caída del peronismo indefectiblemente impactó sobre la esperanza de los villeros, pero debemos agregar que posiblemente la desesperanza también se acopló a la realidad que mostraba que en 9 años de gobierno popular la gran mayoría de los villeros no lograron arribar a una vivienda en la ciudad formal. ${ }^{8}$

Si bien creo necesaria esta advertencia, hay que reconocer que en el balance realizado por los villeros, el peronismo sale airoso como espacio de representación de sus intereses: es cierto que no fueron objeto de políticas de vivienda específicas pero sí recibieron asistencia de diverso tipo brindada por organismos públicos de este gobierno. La política anti-popular llevada a cabo por la Revolución Libertadora no hizo más que intensificar la convicción de que el peronismo sería el único capaz de mejorar su situación. La desilusión villera ante la caída y proscripción del peronismo fue uno de los elementos que habilitó el nuevo auto reconocimiento donde la villa se empezó a considerar como lugar estable de residencia ${ }^{9}$ y sobre esta idea se construyó una identidad propia como sector específico en el entramado social. Esto les permitió definir sus necesidades y reivindicaciones propias, las cuales no podían ser subsumidas a las demandas de otros espacios políticos y transformó los modos de organización colectiva.

Otro elemento que contribuyó a la asunción de una identidad en tanto villeros, fue que por primera vez el Estado creó y aplicó una política específicamente diseñada para las villas, el Plan de Emergencia de la Revolución Libertadora. El reconocimiento por parte de un agente externo tuvo implicancias en la construcción identitaria, ya no fue solamente la auto conciencia de saber que la villa se comenzó a configurar como un lugar de residencia estable sino que la distinción y reconocimiento por parte del Estado también cooperó en su definición.

De este modo, podemos establecer esta construcción identitaria en torno a dos registros: por un lado, la desilusión de los villeros tras la caída del peronismo; y, por otro lado, el reconocimiento de las villas como problema por parte del Estado. El primer registro implica un cambio de auto conciencia al interior del grupo social, mientras que el segundo implica el reconocimiento por parte de un agente externo de central importancia como es el Estado.

Paralelamente a este proceso, la coyuntura política tuvo repercusiones concretas en las villas: la presencia de cuadros políticos de la incipiente Resistencia Peronista colaboró e incentivó una nueva etapa organizativa en las villas. Estos referentes eran trabajadores que a razón de la

8 Esta idea se encuentra desarrollada en la tesis doctoral de la autora titulada Politicidad Villera, El Movimiento Villero Peronista (UBA, 2014).

${ }^{9}$ Es necesario destacar y recordar que tiene mucho de frustrante, puesto que no era el objetivo de las familias migrantes residir en situaciones de tal precariedad y al margen de la legalidad. 
intervención de los gremios, situación generalizada a partir del golpe de Estado, se sumaron a la denominada Resistencia. La intervención del peronismo en los barrios en estos momentos estuvo caracterizada por la actuación de dirigentes dispersos pero muy respetados en el territorio.

Asimismo, diferentes partidos políticos de la izquierda institucional evaluaron la coyuntura como una oportunidad para ganar a sectores peronistas para su proyecto. Intentar revertir la identidad política de amplios sectores populares fue un punto de contacto entre algunos partidos de izquierda y los militares: desperonizar era un objetivo compartido. El Partido Comunista es el referente de la izquierda que nos convoca en nuestro tema en particular, ya que para el año 1958 creó la Federación de Villas y Barrios de Emergencia de la Capital Federal, organización política que tenía por objetivo intervenir en las villas para intentar redireccionar la afinidad política de los villeros.

Años anteriores, la villa había estado acallada discursivamente, pero desde que el Estado aplicó una política ante ella, el Plan de 1956, sobre el que volveremos más adelante, diferentes sectores políticos y de la sociedad civil comenzaron a acercarse a este sector con diferentes intereses.

La confluencia de estos tres aspectos: la desilusión villera provocada por la proscripción del peronismo que se tradujo en la idea de permanencia duradera en la villa, el reconocimiento de las villas por parte del Estado y la acción del Partido Comunista, estimuló la conformación de la primera organización política de los villeros en tanto sector social.

\section{La Federación de Villas y Barrios de Emergencia de la Capital Federal}

Enmarcada en la estrategia política del Partido Comunista (en adelante $P C$ ), en el año 1958 se formó la Federación de Villas y Barrios de Emergencia de la Capital Federal (en adelante Federación). Ésta fue la primera organización político- sectorial de los villeros.

¿A qué nos referimos al hablar de sectorial? En este caso, se hace alusión a la organización gremial en fábricas e industrias por sector. Si bien es muy diferente el tipo de organización política que puede desarrollarse al interior de una fábrica y el que puede desarrollarse en una villa, se encuentran ciertas analogías que permiten trasponer el término: las villas se organizaron con cuerpos de delegados por manzanas, se votaba una comisión representante de la villa y sus demandas iniciales requerían mejoras en las condiciones de habitabilidad del barrio -al tiempo que las demandas iniciales de cualquier organización gremial parte de mejoras en las condiciones de trabajo-. Así, lo sectorial será utilizado como sinónimo de político, si acordamos en entender las luchas gremiales y las luchas territoriales como pujas de poder.

Es necesario destacar que el sector villero es un colectivo que se conforma en el territorio y no en el proceso productivo, siendo su pretensión más general la demanda por una vivienda digna. De esta manera, su reivindicación fundamental se enmarca en el ámbito del 
consumo, por definición disgregador, situación que los distancia de la identidad obrera construida en el ámbito de la producción. Pero las particularidades que fueron asumiendo las organizaciones villeras lograron superar la tendencia disgregadora y arribaron a situaciones muy similares a las desplegadas por las luchas meramente obreras.

Así, cuando se utiliza el término sectorial, se hace referencia a la organización política que se dio la villa destinada a defender las demandas de los villeros en tanto sector social.

Volviendo a la primera organización político- sectorial de los villeros, el lanzamiento de una federación destinada a organizar a las villas de la Ciudad de Buenos Aires debe leerse en el contexto de la estrategia general esgrimida por el $P C$ a partir de la proscripción del peronismo. En relación a la clase obrera, el $P C$ adoptó "una línea de trabajo junto a los obreros peronistas en defensa de las condiciones laborales y la permanencia de los delegados gremiales" (James, 1999,p. 99). Los militantes comunistas fueron aceptados por los obreros peronistas en lo concerniente a las acciones de corto plazo, es decir, fueron aliados en las peleas al interior de las fábricas. Fuera de esos límites, el $P C$ despertaba gran desconfianza y hostilidad debido al histórico antiperonismo del partido. Si bien fue clara la intención del $P C$ en acercarse al peronismo intentando una empatía política en el contexto dictatorial, el objetivo de máxima convencer que el movimiento nacional y popular no defendía genuinamente los intereses de la clase obrera y que, por el contrario, la organización del partido sí podía representar- no fue logrado.

El comunismo como horizonte político no logró cosechar adhesiones mayoritarias entre los obreros y, en general, entre los sectores populares argentinos, quienes continuaron identificados con el movimiento peronista.

El ejemplo de la estrategia dirigida a la clase obrera sirve de matriz para analizar la experiencia de la Federación. De modo casi equivalente a lo acontecido en las fábricas, el objetivo de esta organización fue acercarse a los villeros peronistas con el fin de conquistarlos políticamente, pero el grueso de la población villera mantuvo una relación de tipo instrumental con la Federación, enmarcada en la búsqueda de canales de demanda ante instituciones estatales.

\footnotetext{
La Federación (...) surge en una coyuntura en que las condiciones de vida de la clase trabajadora sufren un gran deterioro y en que la actuación del peronismo estaba prohibida. Esto último hace que el Partido Comunista trate de ocupar su espacio político teniendo un real peso en la dirección y orientación de las reivindicaciones populares, a lo que ayuda su legalidad y el hecho de tener representantes en organismos estatales (Pastrana, 1980, p. 131).
}

En esta línea, podemos identificar que la asunción de una identidad específica en tanto villeros devino en la conformación de un sector social en el marco de la sociedad civil y que inmediatamente este "nuevo" sector social comenzó a desenvolverse como un resuelto actor político. 
Lo paradójico es que a nivel organizativo esa autoconciencia se desdobla en un movimiento contradictorio causado por la prohibición del peronismo como referente político. Tal como manifiesta un entrevistado haciendo referencia a la Villa 31 :

\begin{abstract}
En aquel momento era fuerte la Federación. (...) tampoco tenía fuerza el peronismo porque como estaba proscripto.... y el Partido Comunista no actuaba libremente pero tenía amplia libertad para entrar, además amplia libertad para decir: «nosotros somos la Federación» y armar. Y nosotros no podíamos armar desde el peronismo con un nombre que aglutine a los peronistas. Entonces en esta lucha nosotros también de hecho colaboramos con la Federación, porque era el único organismo en el cual nosotros podíamos tener participación, porque no queríamos sectorizar las luchas (Entrevista I).
\end{abstract}

Como puede leerse en el relato, si bien el sector villero logró ubicarse en el entramado político como un actor homogéneo, plasmado en la Federación, la misma no logró socavar la adscripción peronista de los villeros. La participación de algunos pobladores a la organización política liderada por el $P C$ tenía como fundamento el no poder armar desde el peronismo, más que una convicción en el programa planteado desde el partido.

No obstante esta característica de tensión entre la organización política posible y la adscripción ideológica impedida, resulta indudable el crecimiento político del sector villero, sustentado fundamentalmente por la transformación subjetiva de sus habitantes, que reconocieron a la villa como lugar de residencia estable y a los vecinos como compañeros de luchas por mejoras de la vida cotidiana.

Pasemos ahora a observar a la Federación en acción para lograr comprender las transformaciones a nivel de la política sectorial villera. Una de las falencias esenciales en las villas eran los servicios urbanos, todos ellos dependientes del sistema político. Por este motivo, la Federación se vio obligada a entablar un diálogo casi permanente con los sucesivos gobiernos a fin de obtener los servicios elementales de la ciudad. De este modo, era reconocido el rol desempeñado por la Federación en las demandas y negociaciones ante organismos públicos, pero la autoridad y representatividad que disponía en los barrios fue relativizada por algunos de los testimonios relevados para el trabajo: "Federación de Villas era asociado al PC, porque en realidad en aquel tiempo el PC había tomado el mando en las villas, en cinco villas (...). En las demás villas no tenía dominio la Federación" (Entrevista I).

Si bien se puede sospechar una suerte de subestimación de esta experiencia política, basado en la convicción histórica y contemporánea del entrevistado para con el peronismo, más testimonios abonaron a confirmar que la Federación no tuvo amplios alcances en el territorio: otro entrevistado se refirió a la misma diciendo que "la Federación era un sello armado, fue el primer intento de organizar la villa pero se ahogó en su burocracia y en su anti-peronismo. Fue más publicitario que efectivo" (Entrevista C).

Asimismo, en los trabajos escritos acerca de este momento histórico de las villas, puede 
rastrearse cierto consenso en relativizar la fuerza política de la Federación. Tanto Pastrana (1980, p. 135) como Oszlak (1991, p. 152), que reconocen la gestiones ante organismos institucionales llevadas a cabo por esta organización, acuerdan en considerar que su acción tuvo una escasa incidencia y muy poca participación de la población.

De todas maneras, si acordamos que su acción fue limitada también debemos reconocer que fue la única organización sectorial actuante durante este período.

El siguiente programa de la Federación, ${ }^{10}$ fue difundido para ser debatido en los barrios y para que se propongan modificaciones:

LA FEDERACION DE VILLAS Y BARRIOS DE EMERGENCIA DE LA CAPITAL FEDERAL SE COMPROMETE A LUCHAR POR LAS RAZONES Y OBJETIVOS SIGUIENTES

$\left.1^{\circ}\right)$ Derogación de la ley de erradicación.

La ley 17.605 de erradicación de villas y barrios de emergencia ha demostrado que lejos de solucionar el problema de la vivienda de los habitantes de las villas, ha creado otros más graves. Las viviendas «transitorias», que están en vías de transformarse en definitivas, no alcanzan a cubrir las más elementales necesidades de cualquier familia y en muchos aspectos son peores que las de las villas erradicadas. Por otra parte, no se vislumbra, de acuerdo al plan de esta ley, la anhelada solución de las viviendas definitivas.

En tal sentido, la Federación reclama la derogación de la llamada ley 17.605 y su substitución por un plan que dé solución efectiva al problema de la vivienda (...)

$2^{\circ}$ ) Terrenos y materiales de construcción.

Los precios especulativos de las tierras y los materiales de construcción hacen imposible para los trabajadores la solución del problema de su vivienda en forma individual. El Estado deberá liquidar esta escandalosa especulación y establecer un control estricto sobre los precios de los referidos materiales. Se deberán declarar de utilidad pública y expropiarse por el Estado los terrenos de aquellas villas susceptibles de ser transformadas en barrios populares y estables, entregándoseles en propiedad a los actuales ocupantes a bajo precio y con adecuadas facilidades de pago.

$3^{\circ}$ ) Inmediatamente el mejoramiento de las villas.

Mientras no se declare y se dé cumplimiento al plan de construcción masiva de viviendas dignas y definitivas, la Federación propone un plan inmediato de mejoras a las actuales villas y barrios de emergencia (...) Objetivos:

-Anulación de todos los juicios de desalojo y solidaridad con los demandados;

-Dotar de agua corriente a cada villa (...)

-Instalación de alumbrado público y domiciliario;

-Pavimentación de calles y construcción de aceras;

-Construcción de desagües y cloacas;

-Instalación de teléfonos públicos y estafetas postales;

-Establecimiento de servicio de recolección domiciliaria de residuos;

-Construcción e instalación de guarderías, jardines de infantes, comedores infantiles, escuelas de artes y oficios y de capacitación general para jóvenes y adultos;

-Construcción e instalación de escuelas públicas primarias (...);

-Ampliación de los servicios de los dispensarios donde los hubiere y construcción e instalación donde no los haya (...);

${ }^{10}$ Fue publicado en el órgano de prensa de la Federación en su año XII, 1970. Luego del trabajo de archivo este texto se presenta como el más completo y claro para el análisis.

(c) Urbana: Rev. Eletrônica Cent. Interdiscip. Estud. Cid

Campinas (SP)

v.9, n.1 [15] p.182-203

ISSN 1982-0569 
-Provisión de equipos contra incendio y formación de cuerpos de bomberos voluntarios; ${ }^{11}$

Ley de erradicación, expropiación y entrega de terrenos a bajo precio, construcción de viviendas y mejora en las villas: los primeros ejes de lucha planteados son referidos al hábitat y sus implicancias políticas. Posicionarse en contra de la erradicación planteada en la ley $17.605,{ }^{12}$ sancionada durante la dictadura militar encabezada por Juan Carlos Onganía vincula por oposición a la villa contra el gobierno de turno. Asimismo, la exigencia de intervención estatal para traspasar la propiedad de la tierra a los villeros y controlar los precios de materiales para la construcción, asume una interpelación a los modos de acción estatal.

Continúa el programa haciendo referencia a la acción de las organizaciones políticas:

$\left.4^{\circ}\right)$ Respeto de los organismos vecinales.

Los más diversos funcionarios pretenden interferir en la vida de las villas y en la conducción de sus organismos. En tal sentido, se luchará por la no interferencia de delegados de organizaciones oficiales y ajenas a las villas y por el respeto a las organizaciones vecinales, democráticamente elegidas por los vecinos. ${ }^{13}$

Esta práctica de intervención en las organizaciones político-sectoriales de las villas fue una constante en cuanto plan de vivienda se ejecutó desde el Estado. Claramente tal mediación, cargada de recursos materiales y simbólicos, repercutía en la acción de la Federación y es comprensible su repudio.

$6^{\circ}$ ) COINCIDENCIAS CON OTROS OBJETIVOS.

La Federación de Villas y Barrios de Emergencia es una organización social con hombres y mujeres de toda edad, credos y opiniones, que se mancomunan para luchar por concretas aspiraciones, cuyo centro está en el problema de la vivienda y el logro de la que dignamente lo resuelva en forma definitiva y para todos los trabajadores que habitan las villas. Con estos objetivos la Federación impulsa y fomenta la organización de los vecinos en juntas y comisiones, convoca a éstas a ingresar en su seno, las insta a unir sus esfuerzos con otros sectores de la población laboriosa a la que también afecta el problema de la vivienda, a fin de llevar en conjunto la lucha que les es común. Lucha por las aspiraciones concretas e inmediatas, sobre las que se dan cuenta los anteriores puntos de este programa. Pero la Federación no olvida y hace hincapié en que:

-Los salarios y los derechos de los obreros. El problema de la vivienda esta íntimamente ligado al del salario y a los derechos obreros (...) La Federación apoyará los reclamos de salarios en la medida del real aumento del costo de la vida. Apoyará la lucha por la defensa de las conquistas obreras y por la derogación de la legislación antipopular que viola estas conquistas. Por el respeto a las

\footnotetext{
11 "Proyecto de Programa", en La voz de las villas. Órgano de la Federación de Villas y Barrios de Emergencia de la Capital, Año XII, abril 1970, pág. 2- 3.

12 Legisla el PEVE (Plan de Erradicación de Villas de Emergencia de la Capital Federal y el Gran Buenos Aires), 1968, Ministerio de Bienestar Social.

13 "Proyecto de Programa", en La voz de las villas. Órgano de la Federación de Villas y Barrios de Emergencia de la Capital, Año XII, abril 1970, pág. 3.
} 
auténticas representaciones gremiales y cese de la intervención estatal en los sindicatos y en la vida gremial.

-Las villas y la crisis agraria. Las causas de la formación de villas son ampliamente conocidas. A ellas nos han arrojado la crisis agraria, la desocupación y la miseria (...) La Federación apoyará los reclamos de una profunda reforma agraria que termine con los latifundios y entregue tierras aptas a los trabajadores agrarios, campesinos, chacareros, etc. en las condiciones y con medios y créditos que hagan posible su explotación.

$-(\ldots)$

-Cambio de estructuras. Por último, la Federación no olvida que la solución real y definitiva del pavoroso problema de la vivienda obrera, solo puede estar dado dentro del marco de un profundo cambio de estructuras económicas y sociales. En este sentido, declara su propósito de colaborar con todas las fuerzas populares que estén dispuestas a luchar por estos cambios y por un gobierno que los haga posibles. ${ }^{14}$

Este parágrafo plantea explícitamente los objetivos de la Federación que desborda los límites de la villa: se plantea en principio la vinculación con otros sectores con problemas de vivienda y concluye proponiendo el protagonismo del obrero, la inclusión del problema de la estructura agraria nacional y finalmente el planteo de un "cambio de estructuras económicas y sociales", las cuales no son especificadas. De todos modos, al conocer la articulación entre esta organización y el $P C$ resulta comprensible el final del programa pero también hay que destacar la presencia un poco forzada de temas de coyuntura nacional en un momento donde aún se estaba construyendo una mayor conciencia del sector villero en tanto actor político específico.

Podemos concluir que mientras la identidad política de los villeros continuó regida por el peronismo, la acción política estuvo atravesada por la propuesta formulada en las villas por el PC (Ratier, 1973, p. 94). ${ }^{15}$ Probablemente urgidos por las necesidades que acarrea la pobreza, la tensión entre identidad y acción sea una de las características que componen a la praxis política villera.

\section{La acción gubernamental ante las villas}

Existe amplio consenso en definir los años de proscripción del peronismo (1955- 1973) como un momento de inestabilidad política, ${ }^{16}$ fundado en la negación o intento de integración del peronismo y por las sucesivas crisis económicas en que se vio envuelto el país. ${ }^{17}$ Teniendo en cuenta este escenario inestable, se revisan a continuación las políticas dirigidas a las villas por parte de los gobiernos sucedidos entre estos años.

$14 \quad$ Ibidem.

15 Luego de desarrollar la idea sintetizada en esta oración el autor, haciendo referencia a la conciencia de los villeros, afirma: "su conciencia ya estaba fraguada: seguía siendo peronista, con una lealtad y consecuencia que llamó la atención a los «verdaderos revolucionarios»" (Ratier, 1973, p. 95).

16 Portantiero (1977); De Riz (1981); Cavarozzi (2002); Amaral (2004); O 'Donnell (2009). Cada uno pone el énfasis en diferentes variables para explicar la inestabilidad política del período.

17 Véase Richard Gillespie (1998, p. 50-56). 


\subsection{Plan de Emergencia de 1956 de la Revolución Libertadora}

La conformación de la Federación se encontró en estrecha relación con la acción estatal. Durante los años dictatoriales de la autodenominada Revolución Libertadora (1955-1958) por primera vez las villas fueron identificadas como un problema, no sólo habitacional sino también social, y con el fin de resolverlo se implementó la primera erradicación: Plan de Emergencia de 1956, ejecutado por la Comisión Nacional de la Vivienda.

En estos tiempos, en diferentes ciudades latinoamericanas ya habían surgido asentamientos urbanos similares a las villas y fueron foco de atención de organismos internacionales. Así,

En el año 1956, en Colombia, se celebra la $1^{\circ}$ Reunión Técnica Interamericana de Vivienda y Planeamiento de la OEA. En ella se establecen, desde una determinada concepción sobre las causas que ocasionan el surgimiento de este tipo de poblaciones, una serie de lineamientos para evitar su formación y crecimiento y resolver el problema de los que ya existían (Pastrana, 1980, p. 129).

Los planteamientos del Plan de Emergencia de 1956 se sustentaron en los lineamientos propuestos por este organismo internacional. La Comisión Nacional de la Vivienda informaba que existían 21 villas en la Ciudad de Buenos Aires con 33.920 habitantes, representando el 1,4\% de la población de la ciudad (Ziccardi, 1984, p. 178), y su tarea central fue la elaboración del Plan, que

constituía un acabado proyecto mediante el cual se pretendía erradicar el conjunto de las villas de emergencia mediante una decidida acción gubernamental de construcción de viviendas de interés social. Los principales destinatarios serían los pobladores de las villas, los cuales, mediante una subvención estatal, podrían adquirir nuevas unidades habitacionales (Ziccardi, 1984, p. 178).

Para ello se realizó una evaluación de la situación socio-económica de las familias residentes en las villas y en base a los resultados de la misma se proponían diferentes soluciones. Para matrimonios con hijos planteaban dos formas de erradicación: para las familias sin "entradas suficientes" propiciaba créditos hipotecarios con bajo o nulo interés; para las familias con "entradas suficientes" propiciaba el realojamiento. El resto de las situaciones familiares matrimonios sin hijos o matrimonios donde los hijos ya no convivían con los padres, las personas solas, etc- no estaban contempladas como situaciones a tratar dentro del Plan.

Si bien tenía por objetivo eliminar las villas del país, resultó ineficiente y mostró a los villeros la capacidad de ataque del Estado. ${ }^{18}$ Éste fue explícito en el caso de las familias que quedaron completamente desamparadas ante la erradicación y decididamente en los métodos

18 "El plan elaborado para cubrir las necesidades de habitacionales de 34 mil pobladores apenas si terminó en la construcción de 214 viviendas para 1284 personas" (Blaustein, 2001, p. 16). Asimismo, para un análisis detallado del plan véase Oscar Yujnovsky (1984, p. 98-103). 
ejercidos sobre las familias incluidas en el Plan, los cuales hacían un fuerte hincapié en las tareas de "re educación" de los villeros, considerados "inadaptados". A través de un programa de asistencia social dirigido desde el Estado se pretendía la "readaptación social" de los habitantes trasladados a los nuevos barrios, aunque el Plan "no dejaba de señalar que la solución más acertada debería ser «el reintegro de esas agrupaciones humanas a los respectivos lugares de origen y trabajo, de donde fueron arrancados para precipitarlos a la miseria»" (Yujnovsky, 1984, p. 99).

Recordemos que uno de los propósitos de la Revolución Libertadora fue desperonizar al país. En el caso de las villas, el gobierno militar difundió la idea de que su existencia se debía a una despreocupación del peronismo por los sectores populares (Pastrana, 1980, p. 129), en lugar de comprenderla como un fenómeno regional en el marco de los cambios del modelo económico que fue concentrando las fuentes laborales en grandes ciudades, incapaces de absorber en el mercado de la vivienda formal a los nuevos pobladores. Por inexacta, esta idea no conquistó la menor aceptación entre los villeros ni entre los encargados de analizar el fenómeno. Seguidamente, para poner final al conflicto entre peronistas y anti- peronistas, la estrategia seguida por la dictadura militar fue dejar de confrontar con ciertos sectores peronistas y contemplar sus reivindicaciones, con el objetivo de integrarlos y, así, disgregarlo políticamente. Es en este contexto en el que surge el Plan de 1956.

El hecho de que el Estado considere por primera vez al habitante de las villas
como un sector social específico posiblemente se debió a no haber podido lograr
un apoyo significativo a su proyecto político entre las capas populares en el ámbito
sindical. Fracasado este objetivo, lleva a cabo una propuesta de asistencialismo
material en el ámbito del consumo para sectores poblacionales no organizados
(Pastrana, 1980, p. 129).

Si bien esta política de construcción de viviendas respondía a una necesidad del gobierno de atenuar el conflicto social con sectores del peronismo, los modos de ejecución y las lógicas subyacentes al Plan derivaron en el resultado inverso: ante este accionar las villas formaron su propia organización político-sectorial dispuesta a enfrentar los atropellos desplegados desde el Estado. Es interesante pensar este mecanismo de respuesta a la intervención estatal: si bien su intención es "conciliar", su efecto resulta contrario ya que propicia la constitución de una organización que lo demanda y exige. La Federación se convirtió en el organismo representativo de los villeros y en el interlocutor político ante el Estado y ante los diferentes partidos y agrupaciones de la época, aunque su anclaje real en los barrios pareciera haber sido menor. La construcción de una organización representativa de los intereses sectoriales implicó organización y un posicionamiento propio ante los conflictos, alianzas, demandas y negociaciones a realizar con diferentes actores políticos. 


\subsection{Los gobiernos de democracia restringida}

El llamado a elecciones y el retorno al modo democrático de gobierno, estuvieron signados por la permanencia de la proscripción del peronismo, por este motivo hablamos de democracia restringida. Durante el gobierno de Arturo Frondizi (1958-1962), ante la emergencia habitacional del sector villero, se implementaron dos políticas: en principio sólo se intentó finalizar con las obras iniciadas en el gobierno de facto anterior, abandonando el proyecto previsto por la Comisión Nacional de la Vivienda en su momento de mayor alcance, y, seguidamente, se implementó un proyecto de construcción de viviendas prefabricadas conocidas como "medios caños" por la precariedad de las instalaciones: ${ }^{19}$

Eran chapas de cinc curvadas (...) que permitían (...) gozar de mucho mas frío que afuera en invierno y un calor infernal en verano. Se le agregaba una simbólica y tubular letrina (el pozo no llegaba al metro de profundidad) como servicio sanitario (...) Todos saben que la peor casilla villera es mejor que el medio caño (Ratier, 1973, p. 100).

Durante los primeros años del gobierno de Frondizi la coyuntura política para los villeros se presentaba distendida en comparación a la anterior dictadura y los últimos años de la década del cincuenta presentaron un fortalecimiento de la organización villera que logró algunas mejoras en los barrios a través del rellenado de zonas inundables, la apertura de calles internas y la extensión del alumbrado público, facilitando la accesibilidad al lugar, y la suspensión de desalojos (Pastrana, 1980, p. 131- 132 y Cravino, 2010, p. 19). Es importante destacar que las resoluciones estatales destinadas a brindar mejoras de servicios en los barrios, implícitamente legitimaba la presencia de las villas en la ciudad.

Conseguir que el gobierno suministre las mejoras es una forma de legitimar la ocupación ilegal de los terrenos. Además, como la posesión de cierta infraestructura posibilita y motiva la instalación de nuevos grupos familiares, de hecho opera en contra de uno de los postulados permanentes de la política estatal respecto de las villas: el congelamiento de su población (Pastrana, 1980, p. 132).

El gobierno de Arturo Illia (1963-1966) ${ }^{20}$ se enfrentó a la necesidad de ganar consenso popular, en este caso: consenso villero.

Esta preocupación del gobierno nacional por el problema de las villas responde (...) a la importancia que podía adquirir el comportamiento de este sector popular

19 Estas prefabricadas fueron construidas por empresas privadas contratadas por el Estado. Para resolver el problema habitacional se recurrió al pedido de ayuda externa con el fin de obtener el primer crédito internacional de vivienda otorgado por el Banco Interamericano de Desarrollo. Esta política se correspondió con la reorientación del modelo de acumulación de capital que consistió en aumentar la productividad en base a préstamos externos y empresas transnacionales y, consecuentemente, a nueva forma de inserción de la economía argentina a nivel internacional.

${ }^{20} \mathrm{El} 29$ de marzo de 1962 Arturo Frondizi fue derrocado por un golpe de Estado. El cargo presidencial fue ocupado por José María Guido quien permaneció en el mismo hasta la asunción del presidente electo Arturo Illia el 12 de octubre de 1963. 
urbano, en un momento en que las organizaciones sindicales desataban un plan de lucha en oposición a la política gubernamental (Ziccardi, 1984, p. 162).

Teniendo en cuenta que los gobiernos posteriores a los peronistas habían fracasado en sus proyectos para solucionar el problema (tanto la versión erradicadora de 1956 como la política de vivienda de Frondizi), la tarea implicaba ingeniar una política habitacional eficaz para los pobladores. Así, se sancionó la ley nacional 16.601 de 1964 de construcción de viviendas, la cual sostenía que el Ministerio de Obras Públicas tendría a cargo la construcción de viviendas y que los villeros recibirían préstamos gubernamentales a 15 y 30 años de plazo sumamente beneficiosos (Ziccardi, 1984, p. 163 y Oszlak, 1991, p. 151).

Un problema central de esta gestión fue la oposición entre el gobierno nacional y el gobierno municipal. Mientras el gobierno nacional contaba con buena predisposición para la resolución de problemas, firmemente expresado en la ley 16.601, el gobierno de la Capital Federal tuvo una orientación antagónica. Teniendo en cuenta que la mayoría de las villas existentes en el país se encontraban asentadas en Buenos Aires, la ley nacional quedó prácticamente sin efecto.

\subsection{Plan de Erradicación de Villas de Emergencia (PEVE) de la Revolución Argentina}

El golpe de Estado de 1966, liderado por Juan Carlos Onganía, encontró a la Federación poco preparada para enfrentar la nueva coyuntura política. Tanto la organización villera como el resto de las organizaciones políticas, se vieron afectadas en su funcionamiento por el carácter represivo de la dictadura militar. Sin embargo, todos los sectores activaron diferentes alternativas para continuar operando $y$, contrariamente a lo previsto, se incrementó la participación política.

En cuanto a las villas del país, el discurso oficial se excusó en emergentes naturales para iniciar una acción contundente, que ya tenía programada con anterioridad: las inundaciones sucedidas en octubre de 1967 por el desborde de los ríos Matanza y Reconquista en el Área Metropolitana de Buenos Aires, que afectó a la población de las villas ubicadas en las zonas bajas de las cuencas, fue definida como una catástrofe nacional. En consecuencia, en diciembre de 1967, se dictó la ley nacional 17.605 que dio lugar al Plan de Erradicación de Villas de Emergencia de la Capital Federal y el Gran Buenos Aires (en adelante PEVE), editado en 1968 por el Ministerio de Bienestar Social.

EI PEVE contemplaba las siguientes opciones para la población a erradicar, dependiendo de la situación de cada familia: 1) acceso a créditos para construcción de viviendas, en los casos en que se poseyeran terrenos propios; 2) acceso a pasajes gratuitos para trasladarse a otra zona del país; 3) transporte gratuito de casilla a terreno propio; 4) alojamiento en viviendas transitorias previo al ingreso a programas de vivienda definitivas. Para las familias que se incorporaran al programa de viviendas, es decir, aquellas comprendidas en la cuarta opción, se proponían dos programas complementarios: el de erradicación y alojamiento en Núcleos 
Habitacionales de Transición (en adelante NHT), construidos especialmente para el plan, y luego el acceso a la vivienda definitiva. El pasaje por los NHT fue pensado como etapa de transición, donde se preveía que la población se "re educara" para poder usufructuar la potencial vivienda definitiva.

El Plan afirmaba que las causas que habían generado el problema de las villas era el "atraso del país, y que se traducía en la falta de modernización de sus estructuras" (Bellardi- De Paula, 1986, p. 16). Asimismo sostenía:

La convicción de que las causas últimas que generan la aparición de estos núcleos de viviendas improvisadas y clandestinas sean el déficit de vivienda que trae arrastre en el país y el estado de subdesarrollo de alguna de sus regiones que da origen a las migraciones internas, plantea una disyuntiva: o esperar que el mal se remedie en sus causas o hacer algo ya en beneficio de estas familias.

El Gobierno de la Revolución Argentina ha optado por esta segunda alternativa, mientras por otra parte, pone en ejecución importantes proyectos en el interior del país, que a largo plazo detendrán o disminuirán las migraciones hacia Buenos Aires (PEVE, 1968, p. 17).

Las migraciones son comprendidas como problema y la solución propuesta es detenerlas. La Revolución Argentina sólo intervino con la intención de que las familias tengan casa en otras regiones que no sea la Capital Federal, a sabiendas que las causas estaban asentadas en la falta de trabajo en esas zonas.

El Plan requería el cumplimiento de tres instancias por parte de los diferentes organismos involucrados: el congelamiento, que consistía en impedir la formación de nuevas villas, paralizar la construcción de nuevas viviendas en las villas ya existentes y prohibir la instalación de nuevas familias en las viviendas asentadas; el desaliento, que consistía en intervenir perjudicialmente en la vida del barrio para "desalentar" a sus habitantes a su permanencia en el mismo; y erradicación, que consistía en eliminar el total de las villas del Área Metropolitana de Buenos Aires.

Se estimaba terminar con las villas en siete años: en principio se proyectó trasladar a las familias a los NHT, luego de culminado el proceso "re educativo" de un año, pasarían a las viviendas definitivas y una nueva tanda de villeros ingresaría a los NHT para reiniciar el ciclo (Ratier, 1973, p. 104). Pero ambas etapas se desfasaron en el tiempo, el proyecto nunca fue completado y los NHT se transformaron en residencias permanentes, caracterizadas por la precariedad de los materiales, las reducidas dimensiones y algunas de ellas se construyeron en zonas inundables. ${ }^{21}$

\footnotetext{
${ }^{21}$ Se estimaba la construcción de 8.000 unidades habitacionales por año durante un período de siete años, lo que arrojaba un total de 56.000 viviendas. Estas serían destinadas a las supuestas 70.000 familias villeras (20.000 correspondientes a la Capital Federal y 50.000 al Gran Buenos Aires) que merecían ser contempladas en el Plan. Quedaban por fuera del mismo 14.000 familias a las cuales se les ofrecería el resto de opciones dispuestas en el proyecto. "Todo lo que alcanzó a hacerse en los años del onganiato en Capital Federal fue la erradicación - implementada por la Comisión Municipal de la Vivienda- de seis villas
} 
Resulta relevante la siguiente descripción de los NHT, realizada en años inmediatos a su construcción y puesta en funcionamiento, ya que nos brinda un panorama concreto de la propuesta estatal. Son

cubículos de 2,50 $\mathrm{m}$ por $2,50 \mathrm{~m}$ por 2,20 de altura, en material premoldeado (...) La cocina es abierta. Se desperdicia una enorme cantidad de terreno para hacer un patio al frente considerando «la ansiedad de pampa de nuestra gente» (sic), donde se espera que esa gente siembre algo. La ducha del minúsculo bañito está colocada directamente sobre el inodoro a la turca. Por las paredes premoldeadas y el piso de ladrillos se filtra la humedad (...) No se permitiría cerrar, ni ampliar, ni mejorar. La gente debía sentir el «rigor» para apreciar luego el paraíso de la vivienda definitiva" (Ratier, 1973, p. 105).

Los modos de ejecución del PEVE impusieron un control autoritario y absoluto del Estado ante cualquier intento de participación de la organización villera. En el período que abarca este gobierno, no se reconoció a la Federación de Villas como un interlocutor legítimo al tiempo que se impusieron estrictas normas de control por parte de organismos del Estado tanto en las villas existentes como en los $\mathrm{NHT} .{ }^{22}$ Las situaciones concernientes a la vida cotidiana son el mejor ejemplo para ilustrar el carácter autoritario y controlador del Plan:

En el núcleo transitorio es el director el que decide todo. Un reglamento deliberadamente ambiguo lo faculta a aplicar penas pecuniarias o la expulsión lisa y llana por faltas que él considere tales. Cabe acotar que estos directores no son «técnicos sociales» sino (...) suboficiales retirados de la policía o el ejército (Ratier, 1973, p. 102).

El proyecto de "congelar" las villas propició la instalación de un cerco policial en el perímetro de los barrios y de agudización de las razzias y la represión hacia los villeros. El "desaliento" provocó perjuicios en la vida cotidiana de los pobladores. Asimismo, quienes habían comenzado la esperanzada hazaña hacia la vivienda propia, quedaron anclados en los NHT. Allí, además de lo deficitario de su construcción, la vida social fue digitada por la figura del "director". El carácter violento de las erradicaciones y el incumplimiento de los compromisos estatales generó el rechazo y la oposición de los villeros frente a este gobierno, agudizando la contraposición de intereses entre ambos. En este contexto la organización política de las villas de la ciudad profundizó y radicalizó sus demandas como así también empezó a plantear estrategias surgidas de los mismos pobladores para resolver la situación habitacional.

Si bien la Federación continuó trabajando en las villas, durante estos años crecieron considerablemente las Comisiones y Juntas Vecinales enmarcadas en el peronismo, si bien aún el partido continuaba proscripto, para fines de los años sesenta se habilitaron resquicios

miseria habitadas por 848 familias. Es decir un total de 3.765 personas y no las 52.000 o 70.000 previstas" (Blaustein, 2001, p. 32).

22 Los pobladores denominaban a los NHT "villas cuartel" (Blaustein, 2001, p. 35).

(c) Urbana: Rev. Eletrônica Cent. Interdiscip. Estud. Cid

Campinas (SP)

v.9, n.1 [15] p.182-203

ISSN 1982-0569 
informales para la organización territorial desde ese espacio ideológico (Dávolos y otros, 1987, p. 24). De esta manera, la organización villera se vió acrecentada y complejizada.

En términos generales podemos afirmar que si en un primer momento el Plan de Emergencia de 1956 incentivó a la organización de los villeros como sector social, la implementación del PEVE de 1968 logró fortalecer las demandas, las alianzas políticas del mismo y la complejización de su trama política, direccionado a su peronización explícita. La profundización del conflicto social se dejaba traslucir en todos los ámbitos sociales, y las villas de la ciudad no fueron la excepción.

\section{A modo de balance}

Hemos analizado el objetivo desperonizador desplegado por la dictadura militar autodenominada Revolución Libertadora y su fracaso. Paradójicamente, durante la proscripción del peronismo y en las antípodas del afán buscado podemos caracterizar estos años por una intensificación del peronismo en los sectores históricamente identificados con él.

El derrocamiento del peronismo tuvo un impacto muy fuerte en las villas, porque esta situación modificó sustancialmente la identidad de sus habitantes: con el peronismo en el poder los villeros entendieron su paso por la villa como un lugar de tránsito que culminaba en el arribo a una vivienda digna. Sin el gobierno popular esta esperanza perdió sentido y la villa comenzó a conformarse en el lugar de residencia permanente. Los villeros conformaron un nuevo sector social e inmediatamente se desarrollaron organizaciones políticas que adquirieron conciencia de su situación de exclusión y se organizaron para reclamar por sus derechos vulnerados, como el acceso a una vivienda digna. Quien fuera referente en estos años de articular la organización política fue la Federación de Villas y Barrios de Emergencia de la Capital Federal, ideada por el $P C$ para ganar adscriptos en este novedoso sector social, cuya conformación se encuentra en estrecha relación con la acción estatal. Este vínculo fundante se perpetuó a lo largo de toda la historia de la organización del sector villero, puesto que tanto sus reclamos como sus reivindicaciones requerían de la participación estatal.

Entre los planes estatales de gran magnitud desarrollados en el período encontramos al Plan de Emergencia de 1956 y al PEVE (1968) y en ambos casos es interesante resaltar un aspecto compartido: las acciones educativas destinadas a los villeros erradicados y realojados en las viviendas construidas. El Plan de 1956, ofrecía la "re educación" en el barrio ya definitivo, el PEVE planteaba el arribo a la vivienda luego de la etapa educativa propiciada en los NHT, quizá pensada en términos de "premio" por haber aprendido las pautas consideradas necesarias para alcanzar una vivienda digna.

Es interesante destacar dos cuestiones al respecto: en primera instancia, las propuestas "re educativas" y "re adaptativas" de los villeros son la expresión de concepciones discriminatorias hacia este sector, ya que en otras situaciones, como los planes de vivienda propuestos desde el Estado para sectores medios, no se proponen tareas de orientación por 
parte de agentes estatales. Considerar que los villeros necesitan ayuda de los asistentes sociales equivale a subestimar su capacidad como sujetos adultos y autónomos. ¿Qué puede esconder como misterio el acceder al agua en el ámbito doméstico a través de una canilla (mientas que las estrategias en la villa para acceder a dicho recurso requería una odisea de acarrear baldes entre pasillos y escombros)? ¿Qué información indispensable para vivir en una casa con los servicios básicos puede ignorar el villero que logra ser re alojado? Parece evidente que en estos planes se parte de una caracterización del sector villero como un actor social desidioso, evaluación agraviante y estigmatizante que coloca al Estado como oponente a un sector social vulnerable.

Pero principalmente los efectos impactan en un desplazamiento en la responsabilidad del problema: si el villero es un apático, un indolente, la responsabilidad de su situación está depositada en su modo de encarar la vida. Ecuación perversa que intenta esconder las causas reales de situaciones y trayectorias familiares desempleadas, sub-ocupadas, explotadas y corridas de diferentes regiones del país y del continente por la desesperanza y la pobreza. Es sobre la generalización de este discurso sobre el que tuvieron que pelear las diferentes organizaciones villeras para construir una imagen genuina de su condición.

\section{Bibliografía citada}

AMARAL, Samuel y PLOTKIN, Mariano (1993). Perón del exilio al poder. Buenos Aires: Cántaro editores.

BELLARDI, Marta y DE PAULA, Aldo (1986). Villas miseria: origen, erradicación y respuestas populares. Buenos Aires: CEAL.

BLAUSTEIN, Eduardo (2001). Prohibido vivir aquí. Una historia de los planes de erradicación de villas de la última dictadura militar. Buenos Aires: Comisión Municipal de la Vivienda.

CAMELLI, Eva (2014). Politicidad villera. El Movimiento Villero Peronista, 1973- 1976. Tesis de Doctorado en Ciencias Sociales. Facultad de Ciencias Sociales, Universidad de Buenos Aires.

CAVAROZZI, Marcelo (2002). Autoritarismo y democracia. Buenos Aires: Eudeba.

CRAVINO, María Cristina (2006). Las villas de la ciudad. Mercado e informalidad urbana. Buenos Aires: UNGS. 
DÁVOLOS, Patricia; JABBAZ, Marcela y MOLINA, Estela (1987). Movimiento villero y Estado (1966-1976). Buenos Aires: CEAL.

DE RIZ, Liliana (1981). Retorno y derrumbe. El último gobierno peronista. Buenos Aires: Hyspamérica.

FERNÁNDEZ CASTRO, Javier; CRAVINO, María Cristina; TRAJTENGARTZ, Daniela; EPSTEIN, Martín (2010). Barrio 31 Carlos Mugica. Posibilidades y límites del proyecto urbano en contextos de pobreza. Buenos Aires: Instituto de Espacialidad Humana.

GILLESPIE, Richard (1998). Soldados de Perón. Los Montoneros. Buenos Aires: Grijalbo.

JAMES, Daniel (1999). Resistencia e integración. El peronismo y la clase trabajadora argentina 1946- 1976. Buenos Aires: Sudamericana.

LANUSSE, Lucas (2007). Montoneros. El mito de sus 12 fundadores. Buenos Aires: Vergara.

LANUSSE, Lucas (2009). Sembrando vientos. Argentina: del primer peronismo a la masacre de Ezeiza. Buenos Aires: Vergara.

O'DONNELL, Guillermo (2009). El estado burocrático autoritario. Buenos Aires: Prometeo.

OSZLAK, Oscar (1991). Merecer la ciudad. Los pobres y el derecho al espacio urbano. Buenos Aires: Humanitas-CEDES.

PASTRANA, Ernesto (1980). "Historia de una villa miseria de la Ciudad de Buenos Aires (1948-1973)", en Revista Interamericana de Planificación, volumen XIV, No 54, 1980 (págs. 124- 140).

PORTANTIERO, Juan Carlos (1977). "Economía y política en la crisis argentina", en Revista Mexicana de Sociología, No 2, 1977 (págs. 531-564).

RATIER, Hugo (1973). Villeros y villas miseria. Buenos Aires: CEAL.

SNITCOFSKY, Valeria (2011). "Villas de Buenos Aires y conflictos portuarios bajo el gobierno de Onganía: aportes para un análisis de la articulación entre sindicalismo de base y 
organización territorial", en Basualdo, Victoria (coord.) La clase trabajadora argentina en el siglo XX: experiencias de lucha y organización (págs. 51-80). Buenos Aires: Atuel.

YUJNOVSKY, Oscar (1984). Claves políticas del problema habitacional argentino 19551981. Buenos Aires: Grupo Editor Latinoamericano.

ZICCARDI, Alicia (1984). "Villas miseria y favelas: sobre las relaciones entre las instituciones del Estado y la organización social en las democracias de la década del '60", en Ciudades y sistemas urbanos. Economía informal y desorden espacial (págs.159-181). Buenos Aires: CLACSO.

ZICCARDI, Alicia (1977). Políticas de vivienda y movimientos urbanos. El caso de Buenos Aires (1963- 1973). Buenos Aires: Mimeo.

\section{Fuentes históricas citadas:}

"Proyecto de Programa", en La voz de las villas. Órgano de la Federación de Villas y Barrios de Emergencia de la Capital, Año XII, abril 1970.

PEVE (Plan de erradicación de las villas de emergencia de la Capital Federal y del Gran Buenos Aires), Ministerio de Bienestar Social, 1968. 